\title{
AS CONSEQUÊNCIAS DA IDENTIFICAÇÃO \\ DE CANDIDATURAS FICTÍCIAS: CASSAÇÃO DAS ELEITAS E DESINCENTIVOS À REPRESENTATIVIDADE FEMININA NA POLÍTICA
}

\author{
The consequences of identifying fictitious candidacies: removal from office of \\ the elected and disincentives to female representativity in politics
}

Marilda de Paula Silveira

Resumo: A partir do estudo de caso do $\mathrm{Mu}$ nicípio de Valença do Piauí/PI, o presente artigo propõe-se a analisar as consequências das candidaturas femininas fictícias em um partido ou em uma coligação. A persperctiva de análise leva em conta a dificuldade do caso - leading case na matéria - sobretudo porque envolve a possibilidade de cassação de candidatas eleitas, mesmo sem qualquer envolvimento na apontada fraude. Definir consequências para uma ação afirmativa que não veio acompanhada de um sistema de controle e cuja efetividade vem sendo construída em pequenos retalhos não é uma tarefa fácil. Longe disso. São inúmeras as perguntas sem resposta: i) identificada a fraude, quais as consequências da ação? ii) sendo inelegibilidade, a quem deve ser imputada? iii) sendo a cassação do mandato dos eleitos, quem deve ser cassado? iv) havendo candidatas eleitas, considerando que são as destinatárias da proteção da ação afirmativa, seus mandatos devem ser preservados? v) concluindo-se pela cassação de mandatários eleitos, como devem ser ocupadas as cadeiras vagas? Pela recontagem dos votos ou pela realização de novas eleições? As respostas a estas perguntas buscam identificar, enfim, como dar efetividade à ação afirmativa sem opor mais desincentivo à inserção das mulheres na política.

Palavras-chave: Mulheres. Política. Cotas. Candidaturas laranjas. Cassação. Mandato.

\begin{abstract}
Based on the case study of the Municipality of Valença do Piauí/PI, this paper aims to analyze the consequences of fictitious female candidacies in a party or coalition. The perspective of the analysis takes into account the difficulty of the case - leading case under discussion - mainly because it involves the possibility of disqualification of elected candidates, regardless of any involvement in the mentioned fraud. To define consequences for affirmative action that did not come with a control system and whose effectiveness has been built up piecemeal is not an easy task. Far from it. There are countless questions unanswered: i) identified the fraud, what are the consequences of the action? ii) being ineligibility to run, to whom should it be imputed? iii) If the term of office of the elected is to be revoked, who shall be removed? iv) If women candidates are elected, considering that they are the recipients of affirmative action protection, should their terms be preserved? v) Opting for the disqualification of elected representatives, how should the vacant seats be fulfilled? By recounting the votes or by holding new elections? The answers to these questions seek to, finally, identify how to make affirmative action effective without opposing more disincentive to the inclusion of women in politics.
\end{abstract}

Keywords: Women. Politics. Quotas. Fake candidacies. Disqualification. Term. 


\section{Introdução}

No julgamento dos recursos de vereadores do Município de Valença do Piauí/PI, o Tribunal Superior Eleitoral definirá as consequências das candidaturas femininas fictícias (ou candidatas laranjas) em um partido ou em uma coligação (figura que existiu até 2018). Há unanimidade quanto à dificuldade do caso que formará leading case na matéria, sobretudo porque pode levar à cassação de candidatas eleitas, mesmo sem qualquer envolvimento na apontada fraude.

Definir consequências para uma ação afirmativa que não veio acompanhada de um sistema de controle e cuja efetividade vem sendo construída em pequenos retalhos não é uma tarefa fácil. Longe disso. São inúmeras as perguntas sem resposta: i) identificada a fraude, quais as consequências da ação? ii) sendo inelegibilidade, a quem deve ser imputada? iii) sendo a cassação do mandato dos eleitos, quem deve ser cassado? iv) havendo candidatas eleitas, considerando que são as destinatárias da proteção da ação afirmativa, seus mandatos devem ser preservados? v) concluindo-se pela cassação de mandatários eleitos, como devem ser ocupadas as cadeiras vagas? Pela recontagem dos votos ou pela realização de novas eleições?

Os números que quantificam os avanços da representação feminina na política não são significativos.

Para compreender a sub-representação feminina na vida política brasileira, não se pode perder de vista que, até 1962, a mulher era considerada relativamente incapaz e dependia do seu marido para exercer inúmeros direitos. Foi com o estatuto da mulher casada, em 1962, que parte das desigualdades e essa noção de incapacidade foi revogada. Não se tratava, portanto, de simples questão cultural, mas de opção normativa incorporada ao Estado de Direito vigente, amparada por política estatal que se pautava exclusivamente pelo gênero.

Há pouco mais de 30 anos, em 1985, as pesquisadoras Albertina de Oliveira Costa, Carmen Barroso e Cynthia Sarti, da Fundação Carlos Chagas, fizeram um levantamento bibliográfico das pesquisas sobre as mulheres realizadas no Brasil entre 1976 e 1985, e apontam como fatores que dificultaram o trabalho: a "novidade relativa do assunto" e o "terreno de convergência possível entre diferentes disciplinas e terra de ninguém" (COSTA et BARROSO, 1995, p. 5). 
Não é irrelevante, nesse contexto, o fato de que nossa sociedade é composta por aqueles que viveram, foram criados ou são herdeiros do que previa o Código Civil de 1916. Essa constatação reflete a posição cultural de $81 \%$ dos homens brasileiros, os quais consideram viver em uma sociedade machista que reforma estereótipos do que seria papel do homem e da mulher. Não surpreende, portanto, que a sociedade não tenha absorvido culturalmente esse critério de igualdade e que as normas que prevejam requisitos de acesso a partir de uma igualdade formal acabem por aprofundar a exata medida da desigualdade.

É possível que as mulheres não queiram ocupar espaços de poder, ainda que eles estejam tão disponíveis quanto para os homens? É possível que a natureza da atividade política afaste as mulheres dos mandatos eletivos? É possível que as diferenças próprias do gênero impulsionem escolhas profissionais diversas? É possível que a corrupção afaste as mulheres da política? Não há dúvida de que as respostas a essas questões podem ser positivas.

Contudo, o acesso às respostas somente seria possível se os mandatos eletivos fossem, de fato, acessíveis às mulheres em igualdade de condições com os homens. De modo que a decisão por disputar um mandato eletivo fosse realmente viável sem que a questão de gênero se apresentasse, em si, como fator de desequilíbrio.

A literatura apresenta explicações de natureza, as mais diversas para essa sub-representação, incluindo a dupla jornada de trabalho, os baixos incentivos e o ambiente corrupto. A questão que se coloca, portanto, é saber se esse cenário decorre de diferenças naturais e deveria ser aceito (tolerado) ou se é fruto de uma história cujos atores são capazes de perpetuar uma desequiparação que não se justifica em nenhuma medida. A se considerar as pesquisas atuais, essa sub-representação não decorre de um fator natural simplesmente porque as mulheres não querem participar da política. Esse cenário decorre dessa complexidade de fatores e, sobretudo, de uma história que posicionou os homens em grande vantagem frete às mulheres. Como, claro, quem ocupa posição de poder não quer sair e as regras são definidas por quem lá está, o ciclo de desequiparação nunca será interrompido a não ser por uma decisão externa a esse ciclo vicioso. Exatamente aqui, como fator de ruptura, entra a importância das ações afirmativas (como as quotas de gênero). 
A esse cenário, soma-se a absoluta dominação masculina nas posições de dirigentes partidários. Não parece consentâneo nem com a realidade nem com o pressuposto que levou à instituição da ação afirmativa concluir que todas as mulheres que integram um partido ou coligações que lançam candidatas laranja participam de um grande conluio, por definição, e que, portanto, devem atrair as consequências sancionatórias de uma ação. Desvincular essa conclusão da exigência de prova da participação da fraude seria reforçar as razões que afastam as mulheres da vida política e dos mandatos que eventualmente venham a alcançar.

Responder a essas perguntas se tornou um dilema há alguns meses, quando fui procurada para defender duas mulheres eleitas que acabaram cassadas porque teriam sido identificadas candidatas fictícias na coligação que as elegeu. Mas elas não eram as "laranjas" e nem tinham qualquer envolvimento na fraude imputada. E mais: as acusadas de serem "laranjas" eram de outros partidos; eram de partidos que integravam a coligação pela qual se elegeram, mas fizeram suas convenções separadamente - como mandam a lei e a constituição - e protegidas pela autonomia partidária.

Nesse momento, já se formava uma corrente de defesa da "cassação de todo mundo senão essa ação afirmativa de defesa das mulheres não terá efeito nenhume distorcerá o cálculo de representação paritária”.

Mas, no primeiro contato com o dilema da causa, o sinal de "isso não está certo" acendeu, junto à consciência de que o bombardeio de críticas seria inevitável.

A tentativa de considerar todos os argumentos envolveu o estudo das publicacões e o diálogo com alguns colegas que dividem as mesmas preocupações ${ }^{1}$. Esse percurso levou ao convencimento de que a ação afirmativa que busca ampliar as chances de eleger uma mulher não pode ter como resultado a cassação, justamente, de mulheres que se elegem, em meio a tantas adversidades, sem qualquer envolvimento na fraude. Veja: não estamos falando das candidatas laranjas, mas das mulheres eleitas apesar disso.

\footnotetext{
${ }^{1}$ Ana Santano e Luiz Magno publicaram artigo em que compartilham as mesmas preocupações quanto à ação afirmativa sancionadora das mulheres que são o objeto da proteção.<https://www.conjur.com.br/2019-mai-27/opiniao-consequencias-fraudes-candidaturas-femininas>. Ainda: <https://www.focus.jor.br/fraude-as-cotas-de-genero-na-visao-de-tres-advogadas/ e http://genjuridico.com.br/2019/06/06/fraude-cotas-de-genero/>. Extraídos em 1 set. 2019.
} 
Cassá-las seria como punir a vítima; não uma, mas duas vezes: primeiro quando enfrentam todos os injustificáveis filtros partidários e sociais para conquistar uma cadeira, e, depois, quando são cassadas sem praticar absolutamente nenhum ilícito, apesar de seu esforço. Extirpar o mandato das mulheres que se elegeram concretizando a ação afirmativa porque houve fraude alheia (justamente advinda daqueles(as) que aprofundam o ciclo de desigualdade) - seria um absoluto contrassenso democrático. Uma autofagia da ação afirmativa. Mas, sobretudo, será mais um DESINCENTIVO à participação feminina.

É sintomático que, ao menor sinal de que o Tribunal Superior Eleitoral estar se preparando para uma cassação global, uma deputada tenha apresentado projeto de lei retirando a obrigatoriedade das quotas. Projeto este que recebeu parecer favorável de outra deputada. E, apesar das inúmeras reações contrárias ao projeto, que é um absoluto retrocesso, ouve-se recorrentemente: "a cota é importante, mas não queremos correr o risco de cassação por uma fraude de que não tomamos conhecimento".

A honestidade acadêmica exige transparência e a advocacia impõe a consciência de que o advogado não integra o processo como parte, mas apenas representa seus interesses.

Devo dizer, contudo, por respeito a essa honestidade, que o caso tratado neste artigo é diferente. Ele envolve uma causa que também é minha: a ampliação da participação feminina na política. A pretensão de que mais mulheres encontrem seu espaço. $\mathrm{O}$ reconhecimento de que a história acomodou os espaços da política de uma forma desigual que precisa ser reconstruída. E que, sem ação afirmativa, nem duzentos anos serão suficientes para que a isonomia na política seja efetiva e não apenas formal.

Como mulher, integrante de grupos que estudam e que incentivam a liderança feminina, nunca defenderia uma causa contrária à essa ação afirmativa. Nesse sentido é que proponho, para além do caso concreto, que se testem todos os argumentos envolvidos no debate.

No momento em que escrevo esse artigo, o julgamento do caso está suspenso após o voto vista do Min. Og Fernandes. Votaram o Min. Jorge Mussi pela cassação de todos os candidatos e candidatas da coligação e o Min. Edson Fachin e Min. Og Fernandes pela cassação apenas dos candidatos e candidatas que tiverem seu envolvimento na fraude comprovados. Aguardam a Min. Rosa Weber e os Ministros Luís Roberto Barroso, Tarcísio Vieira e Sergio Banhos. 


\section{O tema-problema envolvido no julgamento: as consequências de uma ação de cassação contra a coligação que possui candidatas laranjas}

Em artigo aprovado e que aguarda publicação na Revista da Faculdade de Direito, da Universidade Federal de Minas Gerais (SILVEIRA, 2019), analiso o panorama sobre a legislação brasileira, as principais inovações normativas e as alterações jurisprudênciais voltadas a promover uma maior participação das mulheres na vida política. Naquele trabalho, busquei identificar como a jurisprudência do Tribunal Superior Eleitoral e do Supremo inovaram na implementação de ações afirmativas, com o objetivo de ampliar a representação feminina nas esferas democráticas, os efeitos dessas normas e as propostas que vêm sendo apresentadas como alternativa para se alcançar maior isonomia entre os gêneros nas esferas político-decisórias.

O presente artigo tem um enfoque específico: como dar consequências ao descumprimento da quota de $30 \%$ (trinta por cento) imposta como ação afirmativa aos partidos/coligações para lançamento de candidaturas, sobretudo considerando que, nesse percurso, algumas candidatas (e candidatos) são eleitas - com muito esforço próprio - pelos partidos que praticam a fraude.

Não se desconhece a relevante produção acadêmica - nem a divergência jurisprudencial - a respeito do cabimento das ações de impugnação de mandato eletivo (AIME) e nas ações de investigação judicial eleitoral (AIJEs) que buscam apurar e sancionar a prática de fraude no lançamento de candidatas. Contudo, essa questão processual não é objeto de análise nesse artigo (por todos, citam-se ANDRADE NETO; GRESTA et SANTOS, 2018. p. 277). Parte-se do pressuposto da jurisprudência vigente para as eleições de 2016 (TSE, REspE 149, rel. min. Henrique Neves da Silva), segundo a qual essa investigação é cabível por esses meios processuais.

Diante desse pressuposto, cabe indagar: i) identificada a fraude, quais as consequências da ação? ii) sendo inelegibilidade, a quem deve ser imputada? iii) sendo a cassação do mandato dos eleitos, quem deve ser cassado? iv) havendo candidatas eleitas, considerando que são as destinatárias da proteção da ação afirmativa, seus mandatos devem ser preservados? v) concluindo-se pela cassação de mandatários eleitos, como devem ser ocupadas as cadeiras vagas? Pela recontagem dos votos ou pela realização de novas eleições? 


\section{Vamos às consequências: cassar todos os candidatos incentivaria a redução das fraudes? Uma análise dos incentivos}

Antes de mais nada cabe reafirmar: a ação afirmativa da reserva de vagas é indispensável. Ela busca tornar efetivo o princípio constitucional da igualdade entre homens e mulheres. A questão é saber se a consequência pretendida de cassação global alcança o objetivo de reduzir o chamado "gender gap" ou se acabará por aprofundá-lo, bem como se anular a manifestação de vontade de todos os eleitores que votaram naquele grupo de candidatos, ignorando a extensão da fraude e redistribuindo os votos remanescentes, não distorce, ainda mais, o sistema representativo. Vale dizer que, no caminho do óbvio, cassar mulheres eleitas sem qualquer participação na fraude é atuar na contramão da ação afirmativa.

Todos concordamos que o respeito à cota de representação feminina protege, ao menos, a três bens jurídicos: o direito fundamental à igualdade de gênero; o aperfeiçoamento do modelo representativo com a inserção feminina nos espaços de debate e de decisão; e, finalmente, a liberdade de escolha do eleitor. Divergimos, porém, quanto à forma de dar-lhes concretização.

Os defensores da tese de que, identificada a fraude na cota de gênero, deveria ser cassada toda a coligação ou todo o partido, argumentam que essa não seria apenas uma forma de sancionar, mas de restabelecer o que consideram legitimidade da escolha do eleitor. Seria restituído ao eleitor o direito de escolher, de fato, um cardápio de candidatos com efetivos $30 \%$ de quota de gênero. E, especificamente, argumentam que: i) fosse apurada a ilegalidade no DRAP, todos os registros seriam indeferidos - não há razões para que o mesmo não aconteça na AIJE ou na AIME; ii) a consequência para essas ações é a cassação de registro, diploma ou mandato de todos os responsáveis e, com os beneficiários do ilícito, não seria diferente nesse caso; iii) mesmo os que não foram responsáveis pela fraude, foram beneficiados, pois se elegeram com os votos da coligação; iv) as mulheres, mesmo eleitas e não responsáveis pela fraude, teriam sido beneficiadas pela redução do número de concorrentes.

Embora respeitáveis e defensáveis, com todo o acatamento que merecem, esses não me parecem os argumentos com maior sustentação constitucional. Fazem uma leitura invertida do sistema: partem dos instru- 
mentos processais e não da ação afirmativa (que busca proteger direitos individuais fundamentais) para chegar às consequências da fraude. Embora sustentem a melhor das intenções - dar efetividade à proteção ao enrijecer as consequências do descumprimento - os argumentos expostos anteriormente acabam por dar os incentivos errados para os atores do processo eleitoral.

A pergunta que percorre todos os argumentos é: como uma candidata eleita pode ser cassada e acabar inelegível em virtude de ato de terceiro que frauda justamente a ação afirmativa criada para protegê-la?

Em primeiro lugar, a sanção pelo descumprimento da ação afirmativa tem que militar a favor de sua efetividade e não o contrário, sob pena de violar, ela própria, o direito fundamental que busca proteger. Ora, os mandatos obtidos pelas mulheres eleitas - mesmo com toda a discriminação e as fraudes - não podem ser suprimidos e substituídos pelo recálculo do resultado das eleições, a não ser que elas próprias estejam envolvidas na fraude.

O que está em jogo são a integridade do voto e a efetividade da política de inclusão de mulheres no poder legislativo, é verdade. E, ao se deparar com uma lista de candidatos em que há candidaturas fictícias, o eleitor não escolhe mesmo entre um percentual efeito de $30 \%$ de mulheres. O ponto, contudo, não é esse. O ponto é que: apesar de escolher entre candidatos com número efetivo de mulheres menor de 30\%, o eleitor ainda elegeu mulheres e fez a ação afirmativa ter efetividade.

As candidaturas fictícias têm um único objetivo: aumentar ou manter o número de homens em uma chapa. Em nenhuma hipótese beneficiam as mulheres. Pois vejam: apesar da fraude, apesar da redução das candidatas, apesar de o eleitor ter um rol reduzido de mulheres, os eleitores ainda votaram e elegeram mulheres e a ação afirmativa produziu seus efeitos.

Pois bem: o objetivo da ação afirmativa não é tornar efetivo o princípio constitucional da igualdade entre homens e mulheres e reduzir o chamado "gender gap"? Se apesar da fraude esse objetivo é alcançado e os eleitores se sentem representados por mulheres no poder, como a chamada sanção restituitória pode levar exatamente para o sentido oposto do seu objetivo, que é eleger mulheres?

E não é só: essa cassação de mulheres, como se verá, pretende levar ao recálculo do resultado da eleição com a anulação de parcela relevante 
dos votos. Uma loteria que pode suprimir as mulhere eleitas para dar posse a homens eleitos.

Com todo o acatamento, não é possível concluir que restaurar a legitimidade das escolhas do eleitor porque ele não teria tido acesso ao total abstrato de mulheres candidatas pode levar à cassação, justamente, das mulheres eleitas por esses mesmos eleitores. Chegar-se-ia ao absurdo de dizer que faltou concorrência entre as candidatas mulheres e que, portanto, essse seria um benefício sancionável do ilícito.

Causa, portanto, profunda perplexidade a cassação de mulheres eleitas sem particpação na fraude. É um contrassenso à proteção desse direito fundamental que a garantia de sua efetividade seja superada pela abstrata e potencial integridade de um cardápio de opções. Sobretudo se considerarmos que esses mandatos de mulheres eleitas serão substituídas pelo recálculo dos votos remenescentes que podem ter sido atribuídos, majoritariamente, a homens.

Essa pretensão de cassação global frauda não apenas a efetividade do direito fundamental à igualdade de gênero, mas o próprio sistema representativo, porque: i) o resultado das eleições é recalculado, anulando-se todos os votos de um partido/coligação e considerando apenas uma parcela dos eleitores, de modo que parte significativa da sociedade permanece sem representação; e ii) acaba em uma loteria que pode substituir a representação paritária que era assegurada por essas mulheres por um legislativo composto apenas por homens.

A ação afirmativa que fixa percentual de gênero nas campanhas eleitorais tem como objetivo ampliar a participação das mulheres na política. O controle do cumprimento dessa ação afirmativa, evidentemente, tem o mesmo objetivo: garantir que a finalidade da medida seja alcançada. Com efeito, a sanção a ser aplicada em caso de descumprimento dessa política não pode alcançar objetivo diverso da pauta que se propõe a implementar. Não se pode admitir, portanto, que a sanção pela fraude na ação afirmativa acabe por suprimir mulheres de seus mandatos, reduzir o percentual de mulheres no parlamento, ou pior: afastar ainda mais as mulheres da política.

Como revela pesquisa realizada por Esarey e Chirillo, a participação política feminina é maior em democracias menos corruptas (ACKERMAN, Susan Rose et PALIFKA, Bonnie J. Corruption and Government. Second edition. Cambridge, 2016. p. 244). Mulheres tendem a se afastar 
quando lhes repercutem os efeitos da corrupção. É de se concluir, portanto, ser absoluto desincentivo à participação feminina [aliás, de qualquer cidadão] a cassação de mandato por suposto ilícito de que não participaram, e mais: é impossível que tenham condições fáticas e jurídicas de conhecer e impedir.

No julgamento da ADI 5617/DF², quanto à fixação de piso e teto das cotas do Fundo Partidário destinadas ao financiamento de campa- nhas femininas, o Eminente Ministro Luiz Edson Fachin registra que "os obstáculos para a efetiva participação política das mulheres são ainda mais graves, caso se tenha em conta que é por meio da participação política que as próprias medidas de desequiparação são definidas. Qualquer razão que seja utilizada para impedir que as mulheres participem da elaboração de leis inviabiliza o principal instrumento pelo qual se reduzem as desigualdades. Em razão dessas barreiras à plena inclusão política das mulheres, são, portanto, constitucionalmente legítimas as cotas fixadas em lei a fim de promover a participação política das mulheres, tal como afirma Flávia Piovesan, em obra já citada neste voto".

O Ministro Alexandre de Morais também invoca os parâmetros da razoabilidade e proporcionalidade ao assentar que "não parece razoável e adequada a norma impugnada na presente ação, por não propiciar condições satisfatórias à gradativa ampliação da participação feminina no processo político-eleitoral, estando em descompasso tanto com o referido art. 10, $\$ 3^{\circ}$, da Lei 9.504/1997, como em relação aos preceitos constitucionais de igualdade, de cidadania e de pluralismo político".

Caso emblemático que retrata o descompasso entre a finalidade da norma e o efeito diverso causado foi constatado no julgamento da AdinMC $855 / \mathrm{PR}^{3}$, que analisou lei estadual que determinava a pesagem do botijão de gás GLP na presença do consumidor como elemento de proteção

\footnotetext{
${ }^{2}$ Em que a Suprema Corte declarou a inconstitucionalidade da expressão "três" contida no art. $9^{\circ}$ da Lei 13.165/2015 e deu interpretação conforme à Constituição ao art. 9º da Lei 13.165/2015 de modo a (a) equiparar o patamar legal mínimo de candidaturas femininas (hoje o do art. 10, § 3ํㅡㄹ da Lei 9.504/1997, isto é, ao menos 30\% de cidadãs), ao mínimo de recursos do Fundo Partidário a lhes serem destinados, que deve ser interpretado como também de $30 \%$ do montante do fundo alocado a cada partido, para eleições majoritárias e proporcionais; e (b) fixar que, havendo percentual mais elevado de candidaturas femininas, o mínimo de recursos globais do partido destinados a campanhas lhes seja alocado na mesma proporção; (iii) declarar a inconstitucionalidade, por arrastamento, do $\S 5$ 5-A e do $\S 7^{\circ}$ do art. 44 da Lei 9.096/95.

${ }^{3}$ ADI 855 MC, Relator(a): Min. SEPÚLVEDA PERTENCE, Tribunal Pleno, julgado em 01/07/1993, DJ 01-10-1993 PP-20212 EMENT VOL-01719-01 PP-00071.
} 
ao próprio consumidor. Ainda que a finalidade da norma protetiva a este seja louvável, a Suprema Corte considerou que, na prática, tal medida se mostrava desproporcional, pois onerava o processo, agravando o custo do serviço. Tanto assim que o Eminente Ministro Maurício Correa assentou em seu voto: "estou inteiramente de acordo com o eminente Relator, mas acrescentaria apenas mais um argumento que diz respeito com a questão relativa à razoabilidade. A regra estabelecida por essa norma cria mecanismos de complicação até para o consumidor, trazendo dificuldades insuperáveis. É uma lei, a meu ver, por isso mesmo, de conteúdo talque não guarda nenhum sentido de racionalidade".

O Eminente Ministro Gilmar Mendes registrou em seu voto a competência da Suprema Corte "de verificar se a lei não esvazia o conteúdo de direitos fundamentais e, nesse sentido, temos de examinar a adequação, a necessidade $e$ a proporcionalidade em sentido estrito". Com essas considerações, o STF acabou por afastar a incidência da norma que tinha uma finalidade, mas alcançava fim diverso do pretendido.

Uma avaliação apressada poderia levar à conclusão de que a cassação de todos os integrantes do partido ou da coligação seria uma sanção exemplar. E, de fato, pode parecer. Mas, ela acaba, em um só golpe, aviltando o bem jurídico protegido, desestruturando o sistema de representação proporcional e, tudo isso, sem alcançar a efetividade que pretende. Não restaura a pretendida reequiparação de gênero e, ao mesmo tempo, distorce o sistema representativo.

Diante desse cenário, seria possível dizer: mas há outros casos em que a justiça eleitoral promove a cassação do mandato daqueles que não são responsáveis pelo ilícito. É verdade. O que não é verdade é que esse modelo de restauração da legitimidade das eleições já tenha sido aplicado e seja compatível com a garantia de legitimidade de ações afirmativas. Esse é o ponto de viragem que afasta todo o sistema atual desse leading case e que nos leva ao segundo argumento.

As ações previstas na legislação eleitoral (AIME e AIJE) foram pensadas em um sistema que têm como bem jurídico protegido a liberdade de voto, a moralidade e a legitimidade das eleições concretizadas pelo combate a fraudes, corrupção, compra de votos, uso indevido de recursos na campanha, condutas vedadas e abuso de poder político, econômico e dos meios de comunicação. Esses os bens jurídicos que as ações eleitorais e suas consequências buscaram proteger e restaurar. 
A ação afirmativa das cotas, diferentemente dos tais bens jurídicos em questão, busca dar efetividade ao direito fundamental e à igualdade de gênero. Os pressupostos são diferentes e devem ser considerados. $\mathrm{O}$ instrumento não pode se sobrepor ao objetivo de proteção do direito fundamental.

No caso das candidatas a própria condição de beneficiárias da fraude é anaceitável: qual benefício auferem com a fraude? Não ganham votos, pois as candidatas laranjas auferem zero voto; não garantem mais vagas, pois as vagas ampliadas na coligação ou partido asseguradas pela fraude são as vagas do outro gênero (dos homens). Há quem sustente haver benefício pela redução do número de concorrentes mulheres, já que as laranjas não promovem concorrência efetiva.

Vê-se que esse último argumento é tautológico. A ação afirmativa busca ampliar o número de mulheres eleitas. As fraudes são praticadas por homens que historicamente buscam, justamente, reforçar seus espaços de poder, e por mulheres ainda dispostas a abrir mão desse espaço. Se esse objetivo é alcançado, apesar das fraudes praticadas por esses terceiros, a redução da concorrência não pode ser tratada como benefício para as eleitas. Ao contrário: trata-se de mais um óbice à concretização da igualdade que foi ultrapassado por quem se elegeu. Aquelas que, por seus méritos, vencem às eleições apesar de mais essa força contrária, não podem ser tratadas como beneficiárias. Porque não são. Devem ser tratadas como duplamente vencedoras.

Foi, portanto, partindo de pressupostos bastante diferentes que as ações eleitorais foram construídas tendo como consequência (ainda assim criticada) a cassação dos responsáveis e dos beneficiários pela prática dos ilícitos eleitorais. $\mathrm{O}$ objetivo seria restaurar a legitimidade do processo eleitoral preservando-se a liberdade do voto e a moralidade das eleições. Nunca houve responsáveis ou beneficiários por ilícitos que alcançassem o bloco de todos os candidatos de uma coligação ou de um partido, em eleições proporcionais. Não havia hipótese tal cogitada no sistema.

Nota-se que, para fazer a proteção da efetividade das cotas caber nesse molde das ações eleitorais existentes, é preciso muito esforço. Como o sistema de proteção foi pensado para bens jurídicos diferentes, acaba levando à distorção que fica visível neste caso: a categorização de todos como responsáveis ou beneficiários e sua consequente cassação, subvertendo a garantia da própria ação afirmativa. 
Em terceiro lugar, é preciso enfrentar um argumento consequencialista. Argumenta-se que a cassação de todos os candidatos inibiria a fraude porque favoreceria o controle recíproco entre os candidatos de mesmo partido ou coligação. Entretanto, esse argumento desconsidera que a fraude nas candidaturas fictícias ocorre no momento da escolha das candidatas (em convenção ou pelo órgão que recebeu a delegação de poderes dos convencionais).

Quem participa da fraude tem plena consciência de que está praticando uma ação fraudulenta. Contudo, a descoberta da fraude, nesse momento, é bastante difícil (para não se dizer remota). Antes da campanha se desenrolar, afora os envolvidos na fraude, os outros candidatos não conseguem reunir elementos para chegar à conclusão de que A ou B é apenas uma candidata fictícia ou se tem real disposição para ser candidata. Esses ânimos, aliás, podem mudar ao longo das eleições.

A não ser em hipóteses de delação, confissão ou interceptações (que independem dos demais candidatos), a fraude acaba por se revelar apenas no curso da campanha. O que ocorre, portanto, é que o processo eleitoral revela indícios de uma fraude que já foi praticada, mas estes não são conhecidos no momento da convenção ou do registro.

Enquanto os responsáveis pela fraude estão cientes de sua prática, os demais candidatos são colocados diante de um cenário perverso: não conseguem sequer investigar a fraude antes da campanha começar, porque seus indícios estão ocultos; iniciada a campanha, precisam contar com a sorte para que os indícios de fraude apareçam antes do julgamento do DRAP, a fim de que haja tempo de ajustar os percentuais de gênero; se a fraude for descoberta em AIME ou AIJE, a prevalecer a tese da cassação de todos, seu destino estará traçado a reboque dos fraudadores, sem que absolutamente nada pudessem fazer.

É nesse cenário que se deve falar de incentivos. Para tanto, faz-se necessário simular comportamentos. A pergunta que se coloca é: no momento da escolha das candidatas em convenção, os atuais fraudadores terão menos incentivos para escolher candidatas laranjas? Os demais candidatos terão mais incentivos para fiscalizar e denunciar?

Tratando-se das candidatas fictícias, parece-nos que tendem a não se preocupar com potencial cassação ou com inelegibilidades. Afinal, é justamente seu desinteresse pela campanha e pelo mandato que as caracteriza como laranjas. 
Quanto aos dirigentes partidários ou candidatos em disputa, é possível que se sintam impactados por uma decisão de "cassação global" e mudem seu comportamento. Dependem exclusivamente de si mesmos e o risco de perder as cadeiras não é irrelevante. Entretanto, não se pode ignorar que a alteração da jurisprudência para promover a cassação de todo o DRAP e dos responsáveis em AIJE e AIME não parece ter afastado a propensão dessas pessoas para a prática do ilícito desde então.

Não se pode contar, portanto, com um grande desincentivo que atinja os responsáveis pela fraude. A disposição para esta não depende apenas da sanção potencial. Seria preciso contar com a fiscalização recíproca e suprimir o elemento humano. Nesse ponto, os defensores da "cassação global" afirmam que os demais candidatos teriam mais incentivos para promover o controle recíproco, fiscalizando eventuais laranjas para impedir fraudes na cota. Contudo, com todo o respeito que merecem, cassar todos os candidatos promove incentivo inverso.

No momento da escolha das candidatas em convenção, a fiscalização recíproca ou dos próprios órgãos de controle tem eficácia bastante reduzida. Apenas os envolvidos sabem da fraude. Já no curso da campanha, surgindo indícios da fraude, como todos os candidatos (fraudadores ou não) são colocados na mesma condição, sem possibilidade de reparo, a tendência é a de que se unam e busquem caminhos para se proteger das consequências. Os candidatos tendem a buscar, cada qual, a solução "que maximize seu próprio ganho".

A tendência, portanto, é a de que não fiscalizem ou denunciem, mas a de que busquem mascarar a fraude tornando a campanha um pouco mais competitiva com mínimo engajamento e propaganda para evitar o "zero voto" e o "zero gasto". Ao que nos parece, promove-se um incentivo à união que leva à sofisticação da fraude. Não há incentivos para fiscalização ou imputação recíproca.

Mas não é só: as candidatas de boa-fé, que deveriam ser o foco da proteção pois já enfrentam todos os obstáculos para concorrer e são a razão da ação afirmativa, terão ainda menos incentivos para se inserirem na vida pública. Correm o risco de serem cassadas por fraudes de terceiros, cuja prática não possuem instrumentos para fiscalizar e que, além de tudo, são blindados pela autonomia partidária. Se não bastasse, quando a fraude se torna visível ao longo da campanha eleitoral, já não há mais o que possam fazer. Nesse contexto, resta-lhes aguardar a cassação por arrastamento. Sem 
contar que recebem a tarefa de fiscalizar a campanha alheia, antes e depois de iniciado o processo eleitoral.

A ação afirmativa acaba enfraquecida ao invés de se promover o seu fortalecimento. Não se pode admitir, com todo o respeito, que a sanção pela fraude na ação afirmativa acabe por suprimir mulheres de seus mandatos, reduzir o percentual de mulheres no parlamento ou pior: afastar ainda mais as mulheres da política.

O caso de Valença do Piauí tem ainda uma peculiaridade que atrai um quarto argumento: as eleições em julgamento são as de vereadores em 2016, momento em que ainda havia coligações, e as candidatas fictícias eram de partidos diferentes das candidatas eleitas. Portanto, foram cada qual escolhidas em suas convenções individuais.

De fato, a escolha dos candidatos e candidatas ocorre em convenção que é blindada pela autonomia partidária. Assim porque, nos termos do art. 105, § 2º do Código Eleitoral, os partidos escolhem seus candidatos individualmente em suas convenções, de modo que apenas o registro é promovido conjuntamente, no DRAP ${ }^{4}$. Não encontra fundamento legal e refoge aos objetivos da ação afirmativa, portanto, a afirmação de que os efeitos da fraude lhes alcançaria porque estariam todos na mesma coligação e no mesmo DRAP.

Cria-se a hipótese de cassação perversa: cassa-se uma (o) candidata (o) por um fato [escolha em convenções] em que ele constitucionalmente estava impedido de interferir e cuja fraude somente teria condições de apurar depois das eleições.

Não fosse suficiente a autonomia para escolha em convenção, basta ver que, ao longo da campanha, os gastos dos partidos são individuais. Não há ação conjunta da coligação para arrecadação e gastos na campanha. Da mesma forma, as prestações de contas dos partidos também são individuais, não havendo prestação de contas da coligação a partir do DRAP. E por que esse ponto é relevante?

Porque a suposta fraude na cota de gênero ocorreria no momento em que se faz a escolha de mulheres nas convenções [blindada pela autonomia, como visto]. Mas a efetivação da fraude, com a suposta ausência de campanha, de propaganda e de gastos, somente de concretiza ao longo do

\footnotetext{
${ }^{4}$ Art. $105, \S 22^{\circ}$ Cada partido indicará em convenção os seus candidatos e o registro será promovido em conjunto pela coligação
} 
processo. Tanto é que a jurisprudência do Tribunal Superior Eleitoral firmou-se no sentido de que não basta a ausência de votos para se caracterizar a fraude; é necessário que haja prova de que a mulher foi designada como candidata apenas para preencher o percentual da cota de gênero [o que seria possível apurando-se gastos, ausência de propaganda etc].

Diante desse quadro, não surpreende que mulheres escolhidas em convenção no intuito de serem laranjas acabem eleitas. E que outras, escolhidas sem qualquer pretensão de fraude, acabem desistindo da candidatura e tenham pouco ou nenhum gasto e voto. Dessa forma e considerando que os partidos promovem gastos individuais - sobretudo no fundo especial de financiamento de campanha - e prestam contas individualmente, como se pode atribuir a todos os partidos e candidatos, em coligação, os efeitosde eventual fraude? Como(e quem) podem ser considerados beneficiáriosda prática, especialmente as mulheres eleitas com todo o esforço da ação afirmativa?

Conclusão nesse sentido constitui afronta não apenas à lógica da autonomia partidária, mas também à lógica da ação afirmativa. Seria implantar uma responsabilidade aos partidos e aos candidatos pelo risco absolutamente integral (SILVEIRA, 2014, p. 3) de formarem coligações, agregada a uma responsabilidade de fiscalização de todos os candidatos no momento de escolha em convenções e ao longo da campanha. Para as mulheres eleitas, ora recorrentes, seria uma inversão de ônus da ação afirmativa.

A vingar essa perspectiva, além de cuidar da sua própria campanha (com toda a dificuldade que já é conhecida), as mulheres teriam que ter fiscalizado as convenções de todos os partidos que integraram a coligação, além de ter fiscalizado todas as campanhas de todas as mulheres de todos os partidos que integram sua coligação [para saber se fizeram campanha mesmo]. E a fiscalização coloca-se no passado, porque, a partir de 2.020, não haverá mais coligação em eleições proporcionais, cabendo a todos fiscalizar apenas as ações de seus próprios partidos.

Embora muito remota a possibilidade de se identificar eventual fraude no DRAP, como visto, caso isso ocorresse, ainda seria assegurado ao partido/coligação o direito de ajustar os percentuais de gênero, dando conhecimento da fraude a todos os candidatos. No DRAP, apenas a resistência do partido ou a apuração da fraude posterior à data das eleições seriam capazes de levar à potencial derrubada de todos os candidatos. 
Essa lógica, embora também questionável, difere do sistema de controle da AIJE e da AIME, que parte do pressuposto da cassação sem cogitar a possibilidade de ciência aos afetados com ajustamento de percentuais. Embora ambos tenham sido criados antes da ação afirmativa e estejam sendo emendados para comportar solução que deem efetividade à medida, tais modelos são absolutamente diferentes, e a eles não se aplica a mesma lógica material.

Com todo o acatamento à tese oposta, a pretensão de cassar todos os mandatos da coligação (incluindo o das mulheres eleitas) em razão de suposta fraude pela cota de gênero afronta, além da própria ação afirmativa, um sistema de dispositivos constitucionais e legais a respeito da matéria. E também confronta a jurisprudência eleitoral já formada.

\section{Estudo do Caso Valença: exigência de participação na fraude para cassação e consequências da vacância}

O Município de Valença ${ }^{5}$, localizado no Estado do Piauí, possui 11 vereadores. Nas eleições de 2016, contrariando os índices de baixíssima participação feminina foram eleitas 3 mulheres vereadoras: Iris Moreira (899 votos, PP), Ariana Rosa (490 votos, PMN) e Fátima Caetano (342 votos, PTC).

Verificou-se, ainda, que: as vereadoras eleitas não foram mencionadas como possíveis responsáveis ou corresponsáveis por serem, indicarem ou escolherem candidatas (os) laranjas; os seus respectivos partidos não indicaram nenhuma candidata que seria supostamente laranja; e as vereadoras não participaram das convenções partidárias em que essa escolha das candidatas apontadas como fictícias foi feita.

Os partidos a que se filiaram e pelos quais se elegeram as vereadoras Ariana Rosa e Fátima Caetano (PMN e PTC) estavam coligados a partidos (PROS, PRB, PSL e PR) que teriam praticado a suposta fraude de lançamento de candidaturas laranjas.

As mulheres eleitas não foram candidatas dos partidos a que a suposta fraude foi imputada. A fraude foi imputada às candidatas do PROS e do PRB, na Coligação Compromisso com Valença I [seriam as candidatas Ivaltania Vieira (PROS) e Neide Rosa (PRB)] e do PSL e PR, na coligação Compromisso com Valença II [seriam as candidatas Maria Eugênia Martins

${ }^{5}$ Recurso Especial Eleitoral 19392/TSE. 
(PSL) e Magally da Silva (PR) e Geórgia Verde (PSB)]. As candidatas eleitas são do PTC e do PMN.

Segundo se extrai do acórdão regional, a Coligação Compromisso com Valença I foi composta pelos partidos PTC/PPS/PRB/PROS/PSC, enquanto a Coligação Compromisso com Valença II foi composta pelos partidos PMN/PSB/PDT/PSL/PR/PSDB. As coligações elegeram:

\begin{tabular}{|c|c|c|}
\hline $\begin{array}{c}\text { Coligação Compromisso com Valença } \\
\text { I (PTC/PPS/PRB/PROS/PSC) }\end{array}$ & Nome & $\begin{array}{c}\text { Número de } \\
\text { votos }\end{array}$ \\
\hline PROS & Leonardo Nogueira & 827 \\
\hline PPS & Stenio Rommel & 665 \\
\hline PTC & Fatima do Caetano & 342 \\
\hline
\end{tabular}

\begin{tabular}{|c|c|c|}
\hline $\begin{array}{c}\text { Coligação Compromisso com Valença } \\
\text { II (PMN/PSB/PDT/PSL/PR/PSDB) }\end{array}$ & Nome & $\begin{array}{c}\text { Número de } \\
\text { votos }\end{array}$ \\
\hline PDT & Benoni & 614 \\
\hline PMN & Ariana Rosa & 490 \\
\hline PSDB & Nonatin Soares & 472 \\
\hline
\end{tabular}

Fosse o caso de DRAP e reconhecido o não atendimento aos percentuais legais, segundo José Jairo Gomes, "deverá o juiz notificar a agremiação para, em 72 horas (LE, art. 11, § $3^{\circ}$ ), regularizar a situação". Para o mesmo doutrinador, a não regularização implica o indeferimento do DRAP, "prejudicando todos os pedidos de registro de candidatura apresentados".

Ocorre que, no caso, não se está a tratar de DRAP, mas sim de reconhecimento de fraude após o registro de candidatura e da própria realização do pleito de 2016, em que não só havia outras candidaturas femininas legalmente registradas, como duas delas obtiveram êxito e foram eleitas.

Como visto, não há dúvida de que a barreira da autonomia partidária impõe que cada partido, ainda que coligado, escolha os nomes de seus candidatos em convenção individual. Tal fato deve ser sopesado em casos tais que, depois de formalizado o registro e realizado o pleito com a eleição de mulheres, somente em ação judicial se concluiu pela existência de fraude na distribuição das quotas de gênero.

Especificamente no caso de Valença, cada partido fez sua escolha respeitando, individualmente, a indicação de $30 \%$ de participação feminina. Senão, vejamos: 
COLIGAÇÃO COMPROMISSO COM VALENÇA I - PTC/PPS/PRB/PROS/PSC

\begin{tabular}{|c|l|l|}
\hline PARTIDO & \multicolumn{1}{|c|}{ CANDIDATOS HOMENS } & \multicolumn{1}{c|}{ CANDIDATAS MULHERES } \\
\hline PROS & LEONARDO NOGUEIRA PEREIRA & $\begin{array}{l}\text { IVALTANIA VIEIRA NOGUEIRA } \\
\text { PEREIRA DA SILVA }\end{array}$ \\
\hline PPS & $\begin{array}{l}\text { STENIO ROMMEL DA CRUZ CER- } \\
\text { QUEIRA }\end{array}$ & \\
\hline PTC & $\begin{array}{l}\text { FRANCISCO DE ASSIS RODRI- } \\
\text { GUES TORRES } \\
\text { FRANCISCO NUNES DA COSTA } \\
\text { NETO } \\
\text { OSMAR ALVES DA SILVA } \\
\text { PEDRO JOSÉ DA COSTA }\end{array}$ & $\begin{array}{l}\text { FRANCISCA GERLANDI DA SILVA } \\
\text { LAZARO } \\
\text { MARIA DA CONCEIÇÃO CUNHA } \\
\text { RENATO FRANCISCO BATISTA } \\
\text { MARIA DE FÁTIMA BEZERRA DE } \\
\text { SOUSA CAETANO }\end{array}$ \\
\hline PRB & RAIMUNDO FERREIRA GOMES & MARIA NEIDE DA SILVA ROSA \\
\hline
\end{tabular}

COLIGAÇÃO COMPROMISSO COM VALENÇA II - PMN/PSB/PDT/PSL/PR/PSDB

\begin{tabular}{|c|c|c|}
\hline PARTIDO & CANDIDATOS HOMENS & CANDIDATAS MULHERES \\
\hline PMN & $\begin{array}{l}\text { ATENCIO PEREIRA DE QUEIROGA } \\
\text { CARLOS AUGUSTO DE OLIVEIRA } \\
\text { SANTOS } \\
\text { LEONARDO NUNES EVELIN RO- } \\
\text { DRIGUES } \\
\text { MARIO SILVA LIMA }\end{array}$ & $\begin{array}{l}\text { ARIANA MARIA DE CARVALHO } \\
\text { ROSA } \\
\text { MARIA LUISA DE SOUSA }\end{array}$ \\
\hline PSB & $\begin{array}{l}\text { RAIMUNDO XAVIER DE LIMA } \\
\text { WILTON NUNES FERREIRA }\end{array}$ & GEORGIA LIMA VERDE BRITO \\
\hline PDT & BENONI JOSÉ DE SOUSA & \\
\hline PSL & ANTONIO GOMES DA ROCHA & $\begin{array}{lll}\text { MARIA EUGENIA } & \text { DE } & \text { SOUSA } \\
\text { MARTINS GOMES } & & \end{array}$ \\
\hline PR & $\begin{array}{l}\text { CICERO RAIMUNDO DE SOUSA } \\
\text { JOSÉ GOMES DE ARAUJO }\end{array}$ & MAGALLY DA SILVA COSTA \\
\hline PSDB & $\begin{array}{l}\text { RAIMUNDO NONATO } \\
\text { LIMA }\end{array}$ & \\
\hline
\end{tabular}

Em cenário como esse, como falar que os partidos que de forma alguma participaram da fraude - sobretudo as mulheres eleitas - são beneficiárias do suposto ilícito? No caso em análise, a fraude foi reconhecida em âmbito regional pelo seguinte: "os votos inexpressivos devem ser considerados em relação a outros fatores, como efetiva realização de campanha, análise de prestação de contas para tentar demonstrar uma corrida eleitoral e condições em que foram apresentadas as candidaturas, por exemplo". 
É preciso dizer que, no momento do registro das candidaturas, não se tinha qualquer indicativo de fraude na distribuição de quotas de gênero, de modo que o DRAP e os registros individuais foram deferidos.

Com efeito, tomando-se por referência a autonomia partidária em escolher seus candidatos, ainda que coligado o partido, é de se ter que as consequências de eventual reconhecimento de fraude devem atingir somente aqueles partidos que indicaram as candidaturas tidas por laranja e os candidatos responsáveis pela fraude.

\section{Diante da cassação: como fazer a redistribuição das cadeiras?}

Finalmente, reconhecida a fraude, seja quem for cassado, ocorrerá a vacância antes do encerramento do(s) mandato(s). Passa a ser necessário definir quem ocupará as cadeiras vagas. Aqui o quinto e último argumento que desconstrói a suposta restauração da vontade do eleitor. Cassados todos os mandatos do partido ou da coligação, há, de um lado, quem defenda que devam ser recalculados os votos e redistribuídas as vagas para os candidatos eleitos pelas Coligações remanescentes. Nada mais antidemocrático, com todo o acatamento. Como suprimir o mandato e, portanto, os votos atribuídos ao eleito e não devolver o sufrágio ao povo? Como permitir que apenas uma corrente - sem oposição - permaneça no parlamento?

Em oposição a essa tese, compreendo que, diante da cassação de representantes do legislativo, deve-se iniciar um processo de duas etapas: suprimidos da coligação/partido os votos atribuídos aos candidatos responsáveis pela fraude, é de se verificar se, com esse novo quociente partidário, a Coligação/partido mantém o número de cadeiras a que fez jus no momento em que se proclamou o resultado das eleições. Abertas as vagas, deve-se aplicar o disposto nos art. 56, $\S 2^{\circ}$ da Constituição, e nos arts. 112, 113, 175 e 224 do Código Eleitoral, com realização de novas eleições, pois se trata de hipótese de vacância. Assim será restaurada a pretendida legitimidade do voto.

Entendimento diverso, levaria à possibilidade de o poder legislativo nos municípios e nos estados permanecer com mandato sem oposição. Significa dizer que buscando sancionar a fraude - seja para apenar candidatos e partidos, seja para restituir a legitimidade ao pleito -, a ação afirmativa, além de cassar as mulheres legitimamente eleitas [que nada têm a ver com 
a suposta fraude], suprimiria do eleitor a possibilidade de ver restaurada a suposta quebra de legitimidade. E mais: estaria suprimida a possibilidade de manter a representação proporcional com divergências no legislativo. Teríamos a possibilidade de conviver com um legislativo de um lado só $\left(\right.$ CAGGIANO, 1995, p. 67) ${ }^{6}$.

Essa posição fundamenta-se na jurisprudência do TSE em julgamento do DRAP - em caso, também do Estado do Piauí - Relator Min. Henrique Neves: REspe: 2204 PI, Relator: Min. HENRIQUE NEVES DA SILVA, Data de Julgamento: 01/04/2014, Data de Publicação: DJE - Diário de justiça eletrônico, Tomo 85, Data 09/05/2014.

Pergunta-se: nesse caso, a coligação em que identificada a fraude não sofreu consequências? Claro que sim. Sofreu como consequência: i) a perda dos votos atribuídos a todos os candidatos que concorreram pelos partidos que foram considerados responsáveis pela suposta fraude; ii) o recálculo do quociente partidário em razão da perda desses votos; e iii) a cassação dos candidatos eleitos por esses partidos integrantes da coligação que foram considerados responsáveis pela fraude.

Suprimidos da coligação os votos atribuídos aos candidatos dos partidos responsáveis pela fraude, é de se verificar se, com esse novo quociente partidário, a Coligação mantém o número de cadeiras a que fez jus no momento em que se proclamou o resultado das eleições.

Reduzido o número de cadeiras a que faz jus a coligação, estar-se-á diante da hipótese de vacância, caso em que deve ser aplicado o art. 56, § 2da Constituição. Caso o número de cadeiras a que faz jus a Coligação não seja alterado [mesmo com a redução do número de votos que recebeu], será necessário preencher a cadeira antes ocupada pelo candidato eleito por um partido responsável pela fraude. Nesse caso, incidem os art. 112 e $175, \S 2$ ㅇ do Código Eleitoral, preservados os votos, e serão redefinidos os suplentes, de modo que outro candidato, eleito pela Coligação, passa a ocupar essa cadeira.

Nesse caso, afirma-se que nada estaria sendo alterado na jurisprudência do TSE, que sempre foi pacífica no sentido de determinar recálculo de resultado das eleições em julgamento de registro de candidatura (RRC) ou de partidos políticos (DRAP). Nos julgamentos de AIJE e AIME - seja

\footnotetext{
6 “a oposição, [pois] passa a desempenhar uma competência integrativa e controladora, com o escopo de manter o regime no âmbito das fronteiras democráticas."
} 
por abuso, seja por corrupção ou fraude - sempre foi determinada a posse do suplente ou a realização de novo pleito. Não sendo o caso de realização de novo pleito - por vacância, convoca-se o suplente da coligação.

De todo modo, mesmo no caso em que, comprovado o envolvimento de todos os candidatos eleitos na fraude, não encontre fundamento constitucional a pretensão de se recalcular o resultado das eleições, redistribuindo todas as cadeiras entre os partidos/coligações remanescentes. Deve-se aplicar o disposto nos art. 56, $\S 2^{\circ}$ da Constituição, e nos arts. 112, 113, 175 e 224 do Código Eleitoral, convocando-se novas eleições, pois trata-se de hipótese de vacância.

A pretensão de redistribuição das cadeiras confronta o art. $56, \S 2^{\circ}$ da CR/88 e os arts. 112 e 113 do Código Eleitoral, os quais impõem a realização de novas eleições, caso se depare com vacância que leve à ausência de suplentes no partido/coligação. Até mesmo porque se trata de hipótese de vacância que não diz respeito apenas às cassações que decorrem da cota de gênero, mas de qualquer vacância por razões eleitorais que atinjam o poder legislativo.

A matéria tem tamanha relevância que encontra status constitucional (art. 56, $\S 2^{\circ}$ da $\mathrm{CR} / 88$ ). E não poderia ser diferente, pois significa assegurar, em caso de vacância, que o eleitor garanta a representatividade no parlamento, por meio da situação e da oposição, ainda que algum fato superveniente [seja nulidade, morte etc] leve à ausência de suplência na coligação ou no partido.

Mas, além disso, essa alternativa leva à possibilidade de o poder legislativo nos municípios e nos estados permanecerem um mandato sem oposição. Significa dizer que buscando sancionar os partidos que teriam fraudado a ação afirmativa, além de cassar as mulheres legitimamente eleitas [que nenhuma ligação têm com a suposta fraude], estar-se-ia suprimindo do eleitor os votos que atribuiu aos candidatos sem qualquer quebra de legitimidade. E mais: estaria suprimida a possibilidade de manter a representação proporcional, com divergências, no parlamento. Seria um legislativo de um lado só. Exatamente aí está a razão pela qual devem ser realizadas novas eleições: devolver ao eleitor a possibilidade de formar blocos de oposição.

Com o máximo acatamento à tese contrária, a distorção do raciocínio encontra-se no fato de que a pretensão oposta trata como suplente quem não é. Nos termos dos arts. 112 e 113 do Código Eleitoral, que regu- 
lamentam o art. 56, $\S 2^{\circ}$ da Constituição, os suplentes são apenas do partido ou da Coligação pela qual concorrem. Cassados todos os candidatos do partido ou da Coligação, não haverá mais eleitos pelo partido/coligação e, portanto, não haverá mais suplência. Haverá, portanto, vacância. Em casos tais, está-se diante de hipótese de realização de novas eleições e não de recálculo de resultado.

Note-se que o art. 112 é muito claro ao dispor que se consideram suplentes “da representação partidária [e da Coligação (Lei 7.454/85, art. 4º)] apenas quem é eleito pelo partido ou pela coligação ["I - os mais votados sob a mesma legenda e não eleitos efetivos das listas dos respectivos partidos; II - em caso de empate na votação, na ordem decrescente da idade]. Não há uma suposta lista geral de suplentes caso acabem os candidatos eleitos por uma agremiação ou coligação. Até mesmo porque não há ordem legal prevista entre os partidos/ coligações para se definir qual seria o primeiro a ser chamado.

Justamente para evitar que o eleitor permaneça sem representação do grupo político que elegeu, e que o parlamento permaneça sem grupos de oposição, é que o Código Eleitoral e a Constituição previram que, em qualquer hipótese em que for aberta vaga [note-se que a generalidade do termo não é aleatória], e não havendo suplente, "far-se-á eleição para preenchê-la se faltarem mais de quinze meses para o término do mandato". Faltando mais de quinze meses, a cadeira permanece vazia.

Não há que se cogitar recálculo em AIJE e AIME. Somente estaria em questão o recálculo do resultado caso se estivesse em debate sobre o registro de candidatura ou o próprio DRAP. E por quê? Não bastasse o art. 56, § $2^{\circ}$ da CR/88, o Código Eleitoral também diferencia, coerente com os arts. 112 e 113, também do Código: i) a "nulidade dos votos" dados à candidato inelegível ou não registrado reconhecida até a data das eleições (art. 175, $\left.\S 3^{\circ} \mathrm{e} 4^{\circ}\right)$; ii) da "anulabilidade da votação" em caso de "falsidade, fraude, coação, uso de meios de que trata o art. 237 ou emprego de processo de propaganda ou captação de sufrágio vedado por lei" (art. 222).

Na primeira hipótese, "nulidade dos votos", em razão de indeferimento ou cancelamento de registro (art. 175, $\S 2^{\circ}$ e $3^{\circ}$ ) - hipótese do RRC ou DRAP - o Código Eleitoral, no art. 175, § $3^{\circ}$ prevê a recontagem dos votos quando afirma que os votos somente serão suprimidos do cálculo de vagas do partido ou coligação se o registro estiver indeferido ou cancelado antes das eleições. 
A situação é bastante diversa quando se trata de nulidade decorrente de fraude, passível de ser reconhecida em AIJE ou AIME. Nesses casos, o Código Eleitoral é bastante claro - não bastasse a disposição expressa do art. 56, § 2-da CR/88 - ao dispor que a hipótese é de novas eleições.

Mas há mais: se a nulidade alcançar mais da metade dos votos, toda a eleição será anulada, nos termos do art. 224, caput do Código Eleitoral. Bastaa leitura atenta do dispositivo para se verificar que a norma não trata apenas das eleições ao pleito majoritário em seu caput. Tanto é que o pleito majoritário mereceu tratamento específico no $\S 3^{\circ}$ do dispositivo. O destaque ao pleito majoritário feito no $\S 3^{\circ}$ só reforça que o caput do art. 224 refere-se a todas as eleições, incluindo as proporcionais. Veja o caput do art. 224: "Se a nulidade atingir a mais de metade dos votos do país nas eleições presidenciais, do Estado nas eleições federais e estaduais ou do município nas eleições municipais, julgar-se-ão prejudicadas as demais votações e o Tribunal marcará dia para nova eleição dentro do prazo de 20 (vinte) a 40 (quarenta) dias".

De fato, a jurisprudência do TSE sempre foi pacífica no sentido de que apenas se determina recálculo de resultado das eleições em julgamento de registro de candidatura (RRC) ou de partidos políticos (DRAP). Nos julgamentos de AIJE e AIME - por abuso, corrupção ou fraude sempre foi determinada a posse do suplente ou a realização de novo pleito. A novidade, no caso, é apenas e tão somente a ausência de suplentes, o que atrai a incidência do art. $56, \S 2^{\circ}$ da $\mathrm{CR} / 88$.

É com base nessas razões que se conclui que o resultado de uma ação que determina a cassação de mandatos no poder legislativo não altera em nada o status dos candidatos eleitos pela Coligação ou pelos partidos remanescentes. Estes continuam com as mesmas vagas que obtiveram no dia da eleição. As demais vagas, abertas na hipótese de cassação da chapa, serão preenchidas por novas eleições. Somente a saída de algum candidato eleito pela própria Coligação é que garantiria vaga aos seus suplentes.

\section{Considerações finais}

O presente artigo buscou inicialmente apresentar os aspectos jurídicos, político e econômico que demonstram a real preocupação das instituições públicas nacionais com a representatividade feminina na política.

Os dados apresentados demonstram que, apesar das iniciativas legislativas e jurisprudenciais direcionadas para o incentivo da participação 
feminina, da histórica luta de conquistas de direitos políticos e do impacto econômico da contribuição feminina na sociedade, as mulheres ainda constituem uma minoria política e possuem percentuais baixíssimos de representantes nas esferas de poder, seja a federal, a estadual ou a municipal, em cargos de eleição majoritária ou proporcional.

Diante desse quadro, buscou-se apontar os caminhos que parecem mais consentâneos com a ação afirmativa, em casos de identificação das chamadas candidatas laranjas.

Propõe-se que os efeitos do reconhecimento de eventual fraude nas candidaturas femininas sejam restritos aos candidatos responsáveis pela fraude e aos partidos que indicaram as citadas candidaturas [o que leva em conta a independência das convenções realizadas com a blindagem da autonomia partidária, a autonomia de gastos de cada partido e a prestação de contas individual], mantendo-se hígida a Coligação e decotando-se desta todos os candidatos daquele partido que indicou a candidatura tida por laranja.

Finalmente, defende-se que, reconhecida a fraude após a realização das eleições, em respeito à boa-fé dos demais candidatos, à preservação das candidaturas femininas e à preservação da vontade do eleitor, seja mantida a jurisprudência do TSE e respeitado o disposto no art. 175, § $3^{\circ}$ do Código Eleitoral, com a manutenção dos votos no cálculo do quociente partidário para a própria coligação ou caso apurada hipótese de vacância, seja reconhecida a ausência de suplência, nos termos do art. 112 e 113 do Código Eleitoral e determinada a realização de novas eleições para preenchimento das vagas em vacância, nos termos do art. 56, § $2^{\circ}$ da Constituição.

Por todas as razões expostas, não parece consentâneo com o fundamento constitucional da ação afirmativa, com o pressuposto que levou à sua instituição ou mesmo com a realidade visível, concluir que todas as mulheres que integram um partido ou coligações participam de um grande conluio. E, ainda que assim não fosse, que devam ser, mais uma vez, alijadas da participação política. Dessa fez, como consequência de uma ação constitucional que busca exatamente o contrário.

Por séculos as mulheres sobreviveram aos efeitos perversos de supostas proteções. Desvincular os efeitos da fraude da exigência de prova da participação feminina seria reforçar um das razões que afastam as mulheres da vida política e dos mandatos.

Não parece ser mais o tempo de sobreviver a mais uma aparente proteção que, no fim da história, cassa seu cargo. 


\section{Referências}

ANDRADE NETO, J.; GRESTA, R. M.; SANTOS P. P. dos. Fraude à cota de gênero como fraude à lei: os problemas conceituais e procedimentais decorrentes do combate às candidaturas femininas fictícias. In: FUX, Luiz;PEREIRA, Luiz Fernando Casagrande; AGRA, Walber de Moura (Coord);PECCINI, Luiz Eduardo (Org.). Abuso de poder e perda de mandato.Belo Horizonte: Fórum, 2018 (Tratado de Direito Eleitoral, v. 7.).

DAHLERUP, D. El Uso de cuotas para incrementar la representación políticade la mujer. In: MENDÉZ-MONTALVO, M.; BALLINGTON, J. Mujeres en el

Parlamento. Más allá de los números. Estocolmo: International IDEA, 2002, pp.159172.

GOMES, J. J. Direito Eleitoral. 12. ed. São Paulo: Atlas, 2016.

SACCHET, T. Partidos políticos e sub-representação feminina: um estudo sobre recrutamento legislativo e financiamento de campanhas no Brasil. In: PAIVA, D.; BEZERRA, H. D (Orgs). Mulheres, política e poder. Goiânia:Cânone Editorial, 2011.

SALGADO, E. D.; CALEFFI, R. Propostas para aumentar a participa- ção feminina na política brasileira [on line]. Mai. 2015. Disponível em: < http://www.conjur.com.br/2015-mai-02/propostas-aumentar-participacao-feminina-politica>. Acesso em: 14 ago. 2017.

SILVEIRA, M. de P. Responsabilidade eleitoral por ato de terceiro. Disponível em: http://www.oseleitoralistas.com.br/2013/03/18/os-ilicitos-eleitorais-praticados-por-terceiros-e-o-nexo-de-causalidade-para-responsabi- lizacaodo-candidato/Acesso em: 1 set. 2014.

Marilda de Paula Silveira - Mestre e doutora em Direto Público pela UFMG. Profes-sora de Direito Administrativo e Eleitoral do IDP/EDB e coordenadora acadêmica da pós-graduação em Direito Eleitoral da mesma instituição de ensino superior. Membro do IBRADE e ABRADEP. Pesquisadora líder do Observatório Eleitoral IDP/EDB e Pes-quisadora membro do CEDAU/USP. Coordenadora da Transparência Eleitoral Regional Brasil. Advogada sócia da Silveira e Unes Advogados Associados. 